\title{
Oman's General Foundation Programs: Focus on General Education Principles and Standards
}

\author{
Victoria Tuzlukova \\ Sultan Qaboos University, Muscat, Oman \\ Meenalochana Inguva \\ Sultan Qaboos University, Muscat, Oman \\ Pooja Sancheti \\ Sultan Qaboos University, Muscat, Oman
}

\begin{abstract}
Contemporary research in education has placed the growing emphasis on general education principles and standards intended for empowering students and developing them as personalities with the related discussions set in different socio-cultural and geographical contexts. This paper explores how principles and standards of general education are integrated and implemented to support students' development and enhancement of their skills in the context of the foundation program at Sultan Qaboos University in Oman. In more detail, utilizing personal views and perceptions of the programs' administrators (department heads, program coordinators and course leaders) involved in constructing and offering the English language foundation program courses, this paper explores how principles and standards of general education are integrated and implemented to support students' development and academic growth. A qualitative research paradigm is used to provide detailed descriptions, discuss experiences, achievements, challenges, and inform future decisions. The results demonstrate that the English language foundation program courses have good potential for building solid basis for students' skills and knowledge development, however, more efforts that include revisions in curriculum and teaching practices are required to develop students into educated, responsible and productive citizens for their own advantage and the benefit of the community.
\end{abstract}

Index Terms — general education, principles and standards, foundation program students, skills, Oman

\section{INTRODUCTION}

Education is of crucial importance in relation to the individuals' development and success in the 21st century (Trilling \& Fadel, 2009). In addition to a solid system of education, what is deemed necessary is "the collegiate experience which addresses the knowledge, skills, attitudes and values characteristic of educated persons" (The Virginia Community Colleges Policy Manual, 2011, p.3). Such type of experience is often described in literature as "general education", especially when referring to both the educational foundations of skills, knowledge, habits of mind, and values that prepare students for success in their majors, personal and professional lives after graduation, and to the programs of education (as practiced in some liberal-art colleges and secondary schools) intended to develop students as personalities rather than trained specialists and to transmit a common cultural heritage (General education, 2018, n.p.). Having been developed in response of the local and global communities' call to enhance the quality of higher education teaching and learning, the construct of general education is also aimed at producing coherent curriculum that educates students, attends to their experiences, feelings, and needs (Austin, 2011, n.p.). This understanding is inseparable from a prospect stated by Ban Ki-moon, former United Nations Secretary General (2012), suggesting that quality education is a major impetus in individuals' progress and development.

The guiding principles for the general education programs comprise a number of propositions that best fit them and serve as their foundation, including their general and multidisciplinary nature, high quality, integration with the major programs, incorporation of extracurricular activities, and delivery by highly qualified faculty with appropriate institutional support (Liberal Studies Program 2.0, 2016). Additionally, the general education programs are "not limited by subjects or disciplines, while holding the connections among bodies of knowledge in high esteem" (The Virginia Community Colleges Policy Manual, 2011, p.3).

Research indicates that general education focuses on a number of core areas for its objectives. These areas may include, for example, effective communication, quantitative reasoning and computer literacy, which are constructed on such pillars, as breadth of knowledge, critical thinking, integration of knowledge and social responsibilities (Tuzlukova, Inguva, Sancheti, \& Bayburtsyan, 2018). Palomba and Banta (1999) argue that the outcomes of general education programs are the competencies or goals for learning and development upon which they are based, namely knowledge, skills, attitudes, and values that students will need to be successful in work, family, and community. In education, the 
desirable competencies for students to possess include communication, cultural and social understanding, information literacy, personal development, quantitative reasoning, and scientific reasoning (The Virginia Community Colleges Policy Manual, 2011, p.3). These competencies or general education outcomes, as explained by Leskes and Wright (2005), are cross-cutting skills that need to be encouraged from all the components of education.

The ideas of general education and its outcomes, which are also prevalent in general education literature, overlap significantly with some dimensions in local contexts of teaching and learning. General education programs are designed, for example, to expand students' worldview and knowledge base, give them opportunities to learn outside their areas of familiarity and gain experience and expertise (Liberal Studies Program 2.0, 2016). Indeed, students in different educational contexts have different aptitudes and needs. As a result, to cater to the needs of these students, it is not just desirable but also essential for education to be customized to local circumstances and realities (Peng, McNess, Thomas, Wu, Zhang, Li \& Tian, 2014).

\section{BRIEF OVERVIEW OF GENERAL FOUNDATION PROGRAMS IN OMAN}

General foundation programs are a relatively new phenomenon in Oman' system of education. Similar to other programs of study that use the component "general" in its name, the general foundation programs in Oman can be characterized as formal and structured programs of study designed to prepare students for their postsecondary and higher education studies. In Oman, general foundation programs are provided by country's licensed higher education institutions. These institutions "teach and assess students, and review and improve" (Carroll, Razvi, Goodliffe \& Al Habsi, 2009, p.17) their curriculum in line with the national standards.

The history of general foundation programs in the country's tertiary education institutions goes back to 2008, when, following the decision of the Oman's Higher Education Council, a Ministerial Decision was issued stating the required adoption of these programs by all public and private higher education institutions operating in the country (Oman Academic Standards, 2010). The main goal of the newly adopted general foundation program was to cover the gap between school and higher education (Baporikar \& Ali Shah, 2012) and meet the academic requirements of Englishmedium higher education providers.

The primary focus of the general foundation programs, as stipulated by their developers, is on learning outcomes attained by students as "the result of carefully planned and executed formal programs of study" (Oman Academic Standards, 2010, p.4). For example, the foundation program at Sultan Qaboos University includes such components, as the English language, mathematics, information technology and study skills. These components are offered in both traditional and virtual learning environments where students are given various activities and tasks devised to enhance their learning motivation and help them adjust more easily to university life. The curriculum developed for the program is a truly comprehensive document. It lists the prerequisites for each course and the materials and testing matrixes used. Also, the curriculum includes the learning outcomes along with the necessary descriptors as well as the administrative procedures and rules for both teachers and students. Moreover, it describes the best practices and supporting methodology to be followed thus covering all areas of teaching and learning and providing support and guidance to teachers (Comprehensive Curriculum Document, 2017).

Bowden and Boyle (1995) make it clear that "the quest for quality in any activity is a constant struggle to maximize the extent to which goals have been achieved despite constantly changing contexts: contexts which not only affect both process and outcome but also catalyze changes in goals" (p.12). The general foundation programs offered in Oman's public and private institutions of higher education can be described as "miniature communities" that mirror the social relations and activities of the larger society in which they have been set (Dewey, 1980). To reach and maintain their focus, general foundation programs have been designed and developed by higher education institutions in Oman as complex teaching and learning contexts. These contexts incorporate multiple factors, such as, for example, stake holders, culture of the society, local and global needs of the future citizens, social communities, communication networks, collaboration among various institutions/universities. All these factors support and actively encourage interaction and a sense of community [that] enable learning (Cornell, 2002). To illustrate, addressing the importance given by Oman's government to ensure quality of higher education that responds to the needs and requirements of the 21 st century, Baporikar \& Ali Shah (2012) outline internal and external factors responsible for the acquisition of knowledge and skill in general foundation programs, including motivation, pedagogy/teaching, methodology, curricula, infrastructure, facilities, policies, strategies, and rules. These factors are related to both students and teachers. For example, teacher factors are teachers' knowledge about the subject, background, culture, experience of teaching at different levels and places, self-efficacy, duration of employment at a place, well planned curriculum, issues related to organizational and interpersonal communication, relationships between teachers and students, and monitoring standards. As stated by Sivaraman, Al Balushi and Rao (2014), "it is the effectiveness of teaching that is translated into the skills that the students gain, and in turn is reflected as the employability of the students" (p.29). Student factors that may have an impact on teaching and learning include the family background of a student, socio-economic status of the parents, attitude to learning, awareness about his/her responsibilities as a student, communication skills, working in teams/groups and openness to learning from different perspectives (Creating, 2009). Administrative factors refer to providing safe and secure environment for both teachers and students, awards for teachers and students for their best 
performancesIII, providing all needed support such as good library, technological support and all related policies in place (Contextual factors, 2018).

\section{THE STUDY}

Leithwood (2016) explains that well-functioning departments are powerful centers for improvement. Since administrators are involved in nearly all aspects of their programs, they play integral roles in ensuring these programs function smoothly. Additionally, position based and distributive leadership does not only make difference. It is also related to student outcomes (Mulford, 2003).

Acknowledging the importance of the general foundation programs' administrators (department heads, program coordinators and course leaders), especially those involved in constructing and delivering its English language component courses ranging from general English to English for Specific Purposes, and from English for Humanities to English for Sciences, this study aimed at identifying their views and perceptions about how principles and standards of general education are integrated and implemented into English language foundation program courses to empower and develop students. In particular, the researchers sought for detailed descriptions of the practices in place, experiences, achievements and challenging issues.

\section{A. Methodology}

To provide detailed descriptions and fully explore the established experiences of Oman's higher education institutions' foundation programs with regard to integration of general education principles and standards, and students' development support, a qualitative research paradigm was used (Coyle, 2007) in this study. Particular attention was given to narratives and personal experiences of general foundation programs' administrators (department heads, program coordinators and course leaders) collected through semi-structured face-to-face interviews. The interview questions for the administrators were designed to have an extended conversation with key qualities (Rubin \& Rubin, 2005).

Within the framework of the study, the developed interview questions sought understanding about the processes and phenomena related to general education teaching, learning and outcomes in the framework of the English language area of the general foundation programs in Oman. The questions in the interview asked the participants about their personal stories as both language educators and administrators. To examine situations in depth, questions related to individual practices and experiences of running the foundation programs, including the challenges faced and the successes achieved, were explored. These questions were related, for example, to understanding the concept of general education, providing students with opportunities to develop as personalities, and to following general education principles and standards, such as, to exemplify, effective communication; quantitative reasoning (=application of basic mathematics skills); computer technology and literacy; content knowledge enhancement; critical thinking; integration of knowledge; teaching social responsibilities; study skills and knowledge application; educating students about global and local cultures and intercultural skills and abilities.

\section{B. Participants}

The study involved the general foundation programs in both public and private higher education institutions in Oman's Muscat, Al Batinah, Al Bureimi, Ad Dhahirah, Dhofar and Ash Sharqiyah governorates.

The interviews covered administrators at different positions in foundation programs, which included heads of the English language departments, English language program coordinators and course leaders, but all played integral roles in the development and implementation of the foundation programs' English language components, and brought into discussion diverse experiences, views and perspectives.

The decisions regarding subject selection for interviews were based on the research question, theoretical perspectives, and evidence informing the study (Sargeant, 2012). Other important factors involved participants' beliefs about their own qualifications, years of work experience and subject area, and their motivation to offer and able to achieve an objective and truthful account (Hollway \& Jefferson, 2000). These factors, as explained in the research by Macovec (2018), have a significant influence on the development of the teachers' professional identity. Hence, the subjects sampled were considered by their role as English language administrators and experience of teaching English language foundation program courses to be able to inform important facets and perspectives related to the study. Ten participants in Oman's higher education institutions were interviewed. The participants were approached by an email. The preinterview emails were sent to the potential participants explaining the purpose of the study, seeking their consent and explaining the interviewing and discussion procedures. The participants had rights of confidentiality, anonymity, and voluntary participation in this research.

During the interviews, the participants were firstly asked to share their personal stories both as administrators and English language educators by telling the researchers about how they started working in higher education institutions in Oman, foundation program courses they taught, and describing their teaching and administrative experience in the foundation programs. Then, the researchers sought information about the administrative issues related to the running of the foundation program, e.g. aims, objectives, values, general education principles and standards. These were about the 
participants' views and perceptions of the challenges they faced while supporting the foundation program courses and their personal achievements in relation to programs' effective running and students' development.

The data collected during the interviews was audio recorded, and then transcribed and analyzed by the researchers. Pseudonyms (e.g. Fatima, Ola, Mohammed, Faisal, Tom, Emma, Peter, Sultan, Ali and Jim) were used in place of the participants' names for labelling all collected data. A large amount of descriptive data was obtained and to analyze the data, constant comparative analysis technique was used. Pickard (2007) explains that this technique involves taking one piece of data and judging it with all others that may be related or diverse in order to develop conceptualizations of the potential relations between pieces of data.

\section{Results and Discussion}

The first and most important finding in this study supports the concept of general education as referred to "educational programs that intend to transmit cultural knowledge and develop students as personalities rather than trained specialists" (General education, 2018, n.p.). However, the foundation programs that are currently in place in Oman's tertiary education institutions are constantly developing contexts of teaching and learning (Burns, 2013). Therefore, administering foundation programs is an interesting but challenging event in the professional lives of the administrators. All study participants explained that they were always open to extend all the support to both teachers and students in their departments, programs and courses. This is done, for example, according to Jim, through open door policy, online communication via discussion board, text messages and emails, regular meetings and discussions on academic and administrative points, mediation, mentoring and assistance. The challenges participants face while running the department, program or course, in terms of academic issues and in terms of administrative issues, were mostly, as worded by Fatima, another study participant, due to "insufficient experience in administrative work in a situation of programs' rapid development and expansion". Some other challenges involved, for example, "lack of collaboration between schools and higher education institutions" (Tom), "need to harmonize issues related to organizational, professional and interpersonal communication" (Ali). To illustrate, Ali mentioned the need to keep up with a balance between the senior management's requirements and faculty satisfaction. Mohammed spoke about various faculty-related day-to-day issues which include timetabling, teaching assignments, multinational teaching community with faculty representing different cultures, ways of thinking and dealing with things, and behaviors. He also emphasized the importance of "moving and progressing at the same rate even if the administrative tasks were added", as well as "getting exposure to the maximum number of teaching and professional development opportunities", including teaching a variety of the English foundation program courses, participating in projects on designing, developing, reviewing and revising materials, courses and learning modules. And this experience as explained by Faisal was "very rich". To exemplify, the position helped him to "accumulate a wide knowledge about teaching craft and explore diverse teaching practices". In Emma's view, working in a foundation program was "a rewarding experience". She further went on to say that "it is nice to see student's improving on the targeted skills and learning outcomes, challenging at times though". Mohammed was of the opinion that experience of working in foundation program "enriches" every administrator. In addition, according to Mohammed, administrators were always engaged with faculty support issues. These include, but were not limited to designing and implementing staff development policy, involving teachers in research, initiating and organizing staff development activities, in particular. in-house professional development workshops, seminars, conferences, and training sessions. Ola fully supported Mohammed's views, and to quote her "in order to successfully implement foundation program courses, the most required administrative support should be related to teacher development".

Within the foundation program English language courses that are framed to improve students' skills for further studies and develop their linguistic competency and cognitive skills (Goodliffe, 2010), general education principles and standards are followed, as explained by Jim, "by ensuring they are included in the learning outcomes for each course. These learning outcomes are written as can-do-statements that students review, practice and are assessed on throughout their courses". According to him, to ensure that students are nurtured in discharging their social responsibilities, it's crucial to "work on building a strong relationship with them not only in the role as an administrator, but also as a teacher, guide, and facilitator". His views gain credence corroborating Bobbit (1918) that "human life, however varied, consists in the performance of specific activities. Education that prepares for life is one that prepares definitely and adequately for these specific activities. However numerous and diverse they may be for any social class they can be discovered. This requires that one go out into the world of affairs and discover the particulars of which their affairs consist. These will show the abilities, attitudes, habits, appreciations and forms of knowledge that men need." (p.42).

According to participants' narrations, through the foundation programs students enjoyed series of experiences which were also the objective of the programs. These included, for example, diverse extra-curricular activities that provided more immersive learning environments for the students, such as students' clubs and societies, activities for using English outside the four walls of the classroom, e.g. "The English Souk" and "The Gallery of Nations" (Mohammed), introduction of blending learning components (Emma), numerous opportunities for autonomous learning (Fatima). Other illustrations are from the interviews with Faisal and Peter. While sharing his stories of success and personal achievements in relation to effective running of the foundation program, Faisal mentioned an online course on Moodle platform that was designed to prepare students for college life and features some videos with teaching episodes, handouts and audio scripts. It also provided student involvement in teaching and learning process by giving feedback 
about course books, teaching and learning, challenges in the classroom, and challenges related to the assessment. As per Peter's response, he emphasized that the foundation program courses in his higher education establishment were designed to prepare "students academically and as citizens with a personality". According to him, among most effective activities were seminars and workshops for students on first aid, safe driving, traffic rules, etc. These extra-curricular activities helped students be aware of their social responsibilities, and they grew as socially and inter-personally responsible citizens.

The English language courses offered at the foundation programs in Oman's higher education institutions have good potential for effective integration of general education principles and standards, and building solid basis for students' skills and knowledge development. For example, these include, but are not limited to integrating critical thinking skills in the curriculum, teaching practice, instructional materials and in-house books. To cite an instance, Emma recalled being involved in curriculum revision aimed at identifying the scope for promoting critical thinking skills of the students. According to her, the focus of the foundation program curriculum is on developing students as systematic, analytical and reflective thinkers. Maria mentioned a series of actions taken at her institution to make students better thinkers. These included materials' revision, use of innovative computer-assisted methods of teaching and assessment procedures. Also, all the participants in the study were strong believers of the importance of critical thinking as a key consideration for ensuring student success. To illustrate, Ali explained that "critical thinking could help students gain knowledge, improve their analytical and problem solving skills, and help them assess and reconstruct meaning". He also mentioned that "empowering students with critical thinking skills" may lead to developing them "as mindful communicators who are free from bias".

As maintained by the participants, in terms of its aim, objectives and values, the foundation program English language courses offered at their higher education institutions also follow principles and standards of general education related to effective communication and to educating students about global and local cultures. In Tom's opinion, for example, "global and local cultures are effectively introduced in the text books and supplementary teaching materials for foundation program students". This finding further substantiates several other studies conducted in similar contexts (Al-Busaidi \& Tuzlukova, 2013; Tuzlukova, Inguva, Sancheti \& Bayburtsyan, 2018). However, as perceived by all the participants in this study, more emphasis should be placed on quantitative reasoning, computer technology and literacy, content knowledge enhancement, teaching social responsibilities, study skills and knowledge application, and intercultural skills and abilities.

As for the student support, foundation programs offer students multiple opportunities. Ola, for example, talked about supporting foundation program students through academic advising scheme that involved an academic advising coordinator responsible for ensuring that the advising process was smoothly and properly conducted. She provided the example of writing skill teachers who, in her educational context, supported students in the capacity of academic advisors; and the quantity and frequency of contact hours put by the teacher consequently resulted in the ability to identify students' problems. Fatima gave examples of Tutorial Centers. Student Success Centers were given as an instance of foundation program students' support by Mohammed. In line with Arrand's study (2014) that shows evidence of increased use of peer tutoring as exchanges to enhance the curriculum and support students through transitional stages of university life, the study participants emphasized that peer mediated strategies are becoming essential components of foundation programs. According to them, peer tutoring schemes that involve a wide array of tutoring arrangements, e.g. one student helping another one, one student helping a group of other students to practice language skills, master content and some aspects of the curriculum, etc., are utilized in all the higher education institutions where the participants work.

The stories of success and personal achievements in administering the English language component of the foundation programs at different levels, narrated by the participants, clearly demonstrate that general foundation programs in Oman are implemented to provide students with additional support, place them in the position of active learners, and hone their skills and abilities through a variety of pedagogical approaches and tasks. Some of these stories are also related to learning outside the classroom and developing students as personalities. For example, Jim talked about communitybased projects that became an integrated part of the writing and study skill research project, which provided students with active and authentic learning opportunities. Mohammed shared some very interesting examples of community outreach initiatives. The initiative called 'Together we Communicate' includes several student-centered activities, focusing at developing students' effective communication and critical thinking skills, and teaching them social responsibilities, etc. through charity work and knowledge sharing, like visits to the local hospitals, schools, giving presentations, fundraising, etc. In 'Together we Read' initiative, students and faculty visit elementary schools in Muscat to offer some reading activities for the school students. In preparation to this activity which was a great learning experience for students, they worked hard to choose stories, prepare tasks and activities, games, gifts, etc. As for the community outreach activity called 'Together we Stand against Plagiarism', students conduct visits to secondary schools in Muscat aiming to spread awareness among students regarding issues related to plagiarism and academic integrity. With their simple knowledge on plagiarism, students share their ideas by giving presentations and showing videos of their own.

When the core areas of general education, such as effective communication, quantitative reasoning, and computer literacy, were discussed, the participants emphasized that these areas are embedded in the foundation program 
curriculum with an emphasis on natural progression from less to more complex foundation program courses, but they are "not fully integrated or interdisciplinary" (Fatma). The participants' responses give a picture of a foundation program curriculum in which effective communication, quantitative reasoning, and computer literacy are mainly sustained by integration of knowledge “... through individual educators" initiatives" (Fatma), especially in such aspects, as breadth of knowledge, development of the critical thinking and inculcation of social responsibilities. This result corroborates findings of previous research on general education principles and standards and their incorporation into foundation English language curriculum and teaching practice in similar contexts (Tuzlukova, Inguva, Sancheti \& Bayburtsyan, 2018). Consequently, as Peter described it, "more efforts are required to bring out the potential".

\section{CONCLUSION}

Without any doubt, "the search for evidence to develop high quality, sustainable education systems, continues to intensify as national economies seek to compete globally" (Peng, McNess, Thomas, Wu, Zhang, Li and Tian, 2014, p.77). This study overall aim was to explore views and perceptions of the foundation programs' administrators about how principles and standards of general education are integrated and implemented into English language foundation program courses to empower and develop students. The evidence from the study suggests that the English language foundation program courses offered in Oman's higher education institutions have potential for effective integration of general education principles and standards, and building a solid basis for students' skills and knowledge development. It's a valuable experience for students to grow academically, boost their competencies and skills, and develop as personalities. However, to ensure that foundation program courses follow general education principles and standards, adequately prepare students for the 21 st century teaching and learning and serve as an integrated, interdisciplinary and applied learning opportunity, more efforts are required. These should include, first and foremost, raising awareness of these standards among faculty, revisions in curriculum and teaching practices as well as helping students become more responsible and productive citizens, thus benefiting both students and the community.

\section{ACKNOWLEDGMENTS}

The authors would like to extend their sincere appreciation and gratitude to the Deanship of Research at Sultan Qaboos University for supporting this study by an internal research grant.

\section{REFERENCES}

[1] Al-Busaidi, S. \& V. Tuzlukova. (2013). An introduction: Research on the general foundation programs in Oman. In Al-Busaidi, S. \& V. Tuzlukova (eds.), General foundation programs in higher education in the Sultanate of Oman: Experiences, challenges and considerations for the future. Muscat: Mazoon Press and Publishing, 9-14.

[2] Al Salmi J. (2014). The contextual factors that influence the adoption of Electronic Theses and Dissertations (ETD) programs in the Arab Gulf Universities. In Proceedings of the SLA-AGC 20th Annual Conference. www.qscience.com/doi/pdf/10.5339/qproc.2014.gsla.2 (assessed 1/8/2018)

[3] Arrand, K. (2014). Peer tutoring. Journal of Pedagogical Development, 1(4). https://www.beds.ac.uk/jpd/volume-4-issue1/peer-tutoring (assessed 1/11/2018).

[4] Austin, M.W. (2011). The value of general education. Psychology Today. https://www.psychologytoday.com/blog/ethicseveryone/.../the-value-general-education (assessed 30/3/2018).

[5] Baporikar, N. \& I, Ali Shah. (2012). Quality of higher education in 21st century. A case of Oman. Journal of Educational and Instructional Studies in the World, 2(1), 9-18. http://www.wjeis.org/FileUpload/ds217232/File/02.baporikar.pdf (assessed 12/5/2018).

[6] Bobbitt, F. (1918). The Curriculum, Boston: Houghton Mifflin.

[7] Bowden, J.A. \& P. Boyle (1995). Understanding RMIT's approach to educational quality assurance. Melbourne, EPI Group, RMIT.

[8] Burns, S. (2013). The rest of the iceberg. In Al-Busaidi, S. \& V. Tuzlukova, (eds.), General foundation programs in higher education in the Sultanate of Oman: Experiences, challenges and considerations for the future. Muscat: Mazoon Press and Publishing, 29-34.

[9] Carroll, M., Razvi, S., Goodliffe, T. \& F. Al Habsi. (2009). Progress in developing a national quality management system for higher education in Oman. Quality in Higher Education, 15 (1), 17-27.

[10] Comprehensive Curriculum Document (2017). Centre for Preparatory Studies, Muscat: SQU Printing Press.

[11] Contextual factors can affect the teaching and learning process in a classroom. https://www.scribd.com/document/107160661/Contextual-Factors-Can-Effect-the-Teaching-and-Learning-Process-in-aClassroom (assessed 18/10/2018).

[12] Cornell, P. (2002). The Impact of change in teaching and learning on furniture and the environment.” In Chism, N. \& D. Bickford (eds.), The importance of physical space in creating supportive learning environments. New directions for teaching and learning. 92. San Francisco: Jossey Bass, 33-42.

[13] Coyle, N. (2007). Qualitative research: What this research paradigm has to offer to the understanding of pain. Pain Medicine, 8 (3), 205-206.

[14] Creating effective teaching and learning environments. (2009). http://www.oecd.org/education/school/43023606.pdf (assessed 19/10/2018).

[15] Dewey, J. (1899/1980). The School and society. Carbondale, IL: Southern Illinois University Press. 
[16] General education (2018). Merriam Webster. https://www.merriam-webster.com/dictionary/general\%20education (assessed $12.5 / 2018)$

[17] Goodliffe, T. (2010). Developing National Standards for Foundation Programs in Oman. In Al-Mahrooqi, R. \& V. Tuzlukova (eds.), The Omani ELT Symphony: Maintaining Linguistic and Socio-Cultural Equilibrium. Muscat: Sultan Qaboos University Printing Press, 373-390.

[18] Hollway, W. \& T. Jefferson. (2000). Doing qualitative research differently: Free association, narrative and the interview method. London: Sage Publications.

[19] Leithwood, K. (2016). Department-head leadership for school improvement. Leadership and Policy in Schools, 15(2), 117-140

[20] Leskes, A., \& B.D. Wright. (2005). The art \& science of assessing general education outcomes: A practical guide. Washington, D.C.: Association of American Colleges and Universities.

[21] Liberal Studies Program 2.0. (2016). https://www.wcu.edu/WebFiles/PDFs/LiberalStudiesDocument-Approved-1-27-2016.pdf (assessed 1/9/2018).

[22] Macovec, D. (2018). The teacher's role and professional development. The International Journal of Cognitive Research in $\begin{array}{llll}\text { Science, Engineering and } & \text { (IJCRSEE), } & \text { 6(2). }\end{array}$ http://www.ijcrsee.com/index.php/ijcrsee/issue/view/1/IJCRSEE\%20Volume\%206\%20Issue\%202\%202018.pdf～(assessed 10/10/2018).

[23] Mulford, B. (2003). School leaders: Changing roles and impact on teacher and school effectiveness. A paper commissioned by the Education and Training Policy Division, OECD, for the Activity Attracting, Developing and Retaining Effective Teachers. http://www.oecd.org/education/school/2635399.pdf (assessed 12/10/2018).

[24] Oman Academic Standards for General Foundation Programs. http://www.squ.edu.om/Portals/162/pdf/GFP\%20Standards\%20FINAL.pdf (assessed 23/2/2018).

[25] Palomba, C. A. \& T.W. Banta. (1999). Assessment essentials: Planning, implementing, and improving assessment in higher education. San Francisco: Jossey-Bass.

[26] Peng, J.W. et al. (2014). Emerging perceptions of teacher quality and teacher development in China. International Journal of Educational Development, 34, 77-89.

[27] Pickard, A. J. (2007). Research methods in information. London: Facet.

[28] Rubin, H.J. \& I.S. Rubin. (2005). Qualitative interviewing: The art of hearing data. Thousand Oaks, Calif: Sage Publications.

[29] Sargeant, J. (2012). Qualitative research part II: Participants, analysis, and quality assurance. Journal of Graduate Medical Education, 4(1), 1-3.

[30] Sivaraman, I., Al Balushi, A. \& D.H. Rao. (2014). Understanding Omani students' (University) English language problems. International Journal of Sciences: Basic and Applied Research (IJSBAR), 13(1), 28-35. http://citeseerx.ist.psu.edu/viewdoc/download?doi=10.1.1.800.4914\&rep=rep1\&type=pdf (assessed 15/9/2018).

[31] The Virginia Community Colleges Policy Manual. (2011). http://www.vccs.edu/about/where-we-are/policy-manual/ (assessed $15 / 5 / 2018)$.

[32] Trilling, B., \& Fadel, C. (2009). 21st century skills. San Francisco, CA: John Wiley \& Sons, Inc.

[33] Tuzlukova, V., Inguva, M., Sancheti, P. \& Bayburtsyan, K. (2018). General Education for students' development: A case study in Oman. Asian Journal of Management Sciences and Education. 7(2), 85-98.

[34] UN Secretary-General Ban Ki-Moon launches "Education First" to send every child to school. (2012). http://www.unaids.org/en/resources/presscentre/featurestories/2012/september/20120927educationfirst (assessed 15/5/2018)

Victoria Tuzlukova obtained her PhD in Applied Linguistics from Pyatigorsk University of Foreign Languages in Russia. She has also held a PhD in Comparative Linguistics from Moscow State University since 2002. She has over 30 years teaching and research experience in Russia and Oman. Currently she is on the faculty at the Centre for Preparatory Studies of Sultan Qaboos University in Oman, which she joined in 2006. During her time at the Centre she has been involved in a number of research projects and initiatives. Her research interests focus on sociolinguistics, intercultural communication, foreign language acquisition and the role of culture in foreign language teaching and learning. Dr. Victoria Tuzlukova has presented and published in a broad variety of international conferences and journals.

Meenalochana Inguva has received her $\mathrm{PhD}$ in language teaching and teacher education from the Central Institute of English and foreign Languages, Hyderabad, India. She has more than 30 years of teaching and teacher training experience across various le vels. Currently she is on the faculty at the Centre for Preparatory Studies of Sultan Qaboos University in Oman, which she joined in 2000. During her time at the Centre she has been involved in curriculum design and development for the foundation program courses. Dr. Meenalochana Inguva worked as the Centre's Head of the Curriculum Unit for 3 years and then became the Standing Member of the Central Curriculum Committee. She has conducted several workshops for teachers of English. Her research interests focus on and include class-room based research, inter-cultural communication and evidence-based teaching.

Pooja Sancheti has obtained her Master's degree in English Language and Literature from Himachal Pradesh University in India and has just submitted her M. Phil thesis. She has a collective experience of more than twenty years in teaching English to young adults and training middle school teachers. Currently, she is the Deputy Director for Professional Development and Research at the Centre for Preparatory Studies at Sultan Qaboos University in Oman. Pooja Sancheti has participated in and initiated several material development and review projects. She has presented her ideas through paper presentations and workshops at many international conferences concerning skills development. Pooja's research interests include EFL teaching and testing approaches and using critical thinking skills to enhance language acquisition. She believes that thinking critically is the key to learning, and education is all about pursuit of knowledge. 